\title{
Complement C5a Alters the Membrane Potential of Neutrophils during Hemorrhagic Shock
}

\author{
David A. C. Messerer, ${ }^{1}$ Stephanie Denk, ${ }^{1}$ Karl J. Föhr, ${ }^{2}$ Rebecca Halbgebauer, ${ }^{1}$ \\ Christian K. Braun (D, ${ }^{1}$ Felix Hönes, ${ }^{1}$ Julia Harant, ${ }^{1}$ Michael Fauler, ${ }^{3}$ Manfred Frick, ${ }^{3}$ \\ Benedikt L. Nußbaum, ${ }^{4}$ Peter Radermacher, ${ }^{4}$ Sebastian Hafner, ${ }^{4}$ \\ and Markus S. Huber-Lang ${ }^{1}{ }^{1}$ \\ ${ }^{1}$ Institute of Clinical and Experimental Trauma-Immunology, University Hospital Ulm, 89081 Ulm, Germany \\ ${ }^{2}$ Department of Anesthesiology, University Hospital Ulm, 89081 Ulm, Germany \\ ${ }^{3}$ Institute of General Physiology, Ulm University, 89081 Ulm, Germany \\ ${ }^{4}$ Institute of Anesthesiologic Pathophysiology and Method Development, University Hospital Ulm, 89081 Ulm, Germany \\ Correspondence should be addressed to Markus S. Huber-Lang; markus.huber-lang@uniklinik-ulm.de
}

Received 10 December 2017; Revised 26 February 2018; Accepted 1 April 2018; Published 29 May 2018

Academic Editor: Yona Keisari

Copyright (c) 2018 David A. C. Messerer et al. This is an open access article distributed under the Creative Commons Attribution License, which permits unrestricted use, distribution, and reproduction in any medium, provided the original work is properly cited.

\begin{abstract}
Background. Polymorphonuclear granulocytes (PMN) play a crucial role in host defense. Physiologically, exposure of PMN to the complement activation product $\mathrm{C} 5 \mathrm{a}$ results in a protective response against pathogens, whereas in the case of systemic inflammation, excessive C5a substantially impairs neutrophil functions. To further elucidate the inability of PMN to properly respond to $\mathrm{C} 5 \mathrm{a}$, this study investigates the role of the cellular membrane potential of PMN in response to C5a. Methods. Electrophysiological changes in cellular and mitochondrial membrane potential and intracellular $\mathrm{pH}$ of PMN from human healthy volunteers were determined by flow cytometry after exposure to C5a. Furthermore, PMN from male Bretoncelles-MeishanWillebrand cross-bred pigs before and three hours after severe hemorrhagic shock were analyzed for their electrophysiological response. Results. PMN showed a significant dose- and time-dependent depolarization in response to C5a with a strong response after one minute. The chemotactic peptide fMLP also evoked a significant shift in the membrane potential of PMN. Acidification of the cellular microenvironment significantly enhanced depolarization of PMN. In a clinically relevant model of porcine hemorrhagic shock, the C5a-induced changes in membrane potential of PMN were markedly diminished compared to healthy littermates. Overall, these membrane potential changes may contribute to PMN dysfunction in an inflammatory environment.
\end{abstract}

\section{Introduction}

Innate immunity fulfils a crucial role in host defense as part of the first line of defense against pathogens. In physiological settings, polymorphonuclear leukocytes (PMN) respond to chemoattractants such as activated complement factor 5 (C5a) with cellular migration, increased apoptotic resistance, and elimination of pathogens by generation of reactive oxygen species (ROS) via activation of the NADPH oxidase $[1,2]$.

Systemic inflammation during sepsis or traumatichemorrhagic shock releases a storm of damage- and pathogen-associated molecular patterns (DAMPs and PAMPs, resp.). Although not yet completely unraveled, this plays a role in generating and releasing incompetent neutrophils with a striking discrepancy between preserved morphological integrity and functional incompetence $[3,4]$. In combination with hypoxia and acidosis, this immunological dysfunction may drive the host into infectious complications and multiorgan dysfunction syndrome (MODS) resulting in a devastating mortality [3].

The complement activation product $\mathrm{C} 5 \mathrm{a}$ interacts not only with PMN via abundantly expressed specific receptors $(\mathrm{C} 5 \mathrm{aR} 1=\mathrm{CD} 88$ and $\mathrm{C} 5 \mathrm{aR} 2=\mathrm{C} 5 \mathrm{~L} 2=\mathrm{GPR} 77)[5,6]$ but also with other immune cells and epithelial cells [6]. G-proteinmediated C5aR1 signaling results predominantly in the release of intracellular calcium [5-8] in PMN, which is likely 
triggered by changes of membrane electrophysiology as alterations in membrane potential, ion channel permeability, and fluxes. In this context, changes in membrane potential [9-11] and transient intracellular alkalinization [12-15] represent early hallmarks of PMN activation by fMLP or phorbol myristate acetate (PMA). In contrast, neutrophils in chronic granulomatous disease are characterized by a diminished production of ROS leading to the absence of cellular depolarization and an impaired immune response $[9,16]$. There is a lot of evidence that PMA- or AMLP-driven initial depolarization of PMN is mediated by NADPH oxidase activity followed by a proton-driven compensation ([11, 15-28] and more; see $[29,30]$ for reviews). To define detailed electrophysiological features of the cell membrane including membrane potential, patch-clamp techniques are often applied. However, in the case of electrophysiological PMN characterization, the amount of studies is surprisingly limited. In one study, the resting membrane potential of PMN was proposed to be approximately $-60 \mathrm{mV}$ [31]. Generally, whole-cell patch-clamp approaches may provoke PMN activation by rupture of the cellular membrane and tampering with the intracellular milieu and induce futile phagocytic efforts of the glass pipette (own unpublished observations and $[11,23])$. Albeit there are a few patch-clamp studies on granulocytes which provide valuable information, they can be associated with possible limitations as electrophysical measurements in neutrophils are difficult by nature, for example, description of NADPH oxidase of other cells (eosinophils $[16,19,24]$, the granulocytic cell line HL-60 $[21,22]$, or macrophages [15]), application of intracellular milieu changing ionophores (e.g., valinomycin, gramicidin, and amphotericin) $[11,18,23]$, or the use of enucleated neutrophils $[17,20]$. To avoid these artificial impacts plus vastly increasing the number of measured cells, we characterized and applied a flow cytometry-based approach.

In the present study, we hypothesized that C5a may alter electrophysiological properties as membrane potential, intracellular $\mathrm{pH}$, and mitochondrial membrane potential of PMN. Furthermore, we proposed that the described C5a-induced functional paralysis of PMN during systemic inflammation $[32,33]$ may be associated with impairment of electrophysiological features of the membrane of PMN.

\section{Materials and Methods}

Unless otherwise stated, all chemicals were obtained from Sigma-Aldrich (Darmstadt, Germany).

\subsection{Isolation of Polymorphonuclear Neutrophils from Humans} and Pigs. After approval by the Local Independent Ethics Committee of the University of Ulm (number 244/11 and 94/14) and written informed consent was collected, human blood was drawn by peripheral venous puncture in sodium citrate monovettes. Subjects were healthy males and females between 18 and 35 years without signs of infection or any current medical problems or medication.

Animal experiments were approved by the Federal Authorities for Animal Research, Tübingen, Germany (number 1087), in accordance to the ARRIVE guidelines.
Male Bretoncelles-Meishan-Willebrand cross-bred pigs (median age: 14.5 months, interquartile range: 13 to 16 months; median weight: $68 \mathrm{~kg}$, interquartile range: 61 to $73 \mathrm{~kg}$ ) were purchased from Laboratoire de Thrombose et d'Athérosclérose, Institut des Vaisseaux et du Sang, Hôpital Lariboisière, Paris, France. Animals were sheltered at Oberberghof, Ulm, Germany, until further use. Animals were kept at a cycle of $12 / 12 \mathrm{hr}$ light/darkness and were at least monitored daily.

In brief, hemorrhagic shock was achieved by removal of $30 \%$ of the blood volume followed by titration of the mean arterial pressure at $40 \mathrm{mmHg}$ for a period of $3 \mathrm{hr}$. Samples were taken before and at the end of the $3 \mathrm{hr}$ shock period via a carotid arterial line. To reduce experimental animal numbers, the samples of interest were taken from a subgroup (before further treatment) of the recently published porcine hemorrhagic shock study which provides the detailed protocol including anesthesia, pre- and perioperative fluid management, and the complex instrumentation procedures $[34,35]$. After further interventions (which all occurred after the blood drawing relevant to this study), animals were euthanized under deep anesthesia by injection of potassium chloride. We chose hemorrhagic shock as a DAMP-driven and well-standardized model of significant inflammation as it is accompanied by severe systemic PMN activation [3, 36]. Moreover, it is less likely that there are any potentially influencing effects of external factors such as PAMPs released in sepsis models.

In human and similarly in pigs, PMN were isolated by Ficoll-Hypaque gradient centrifugation and dextran sedimentation. After hypotonic lysis of remaining erythrocytes, cell concentration was adjusted at $2 \times 10^{6}$ per milliliter. Cells were suspended in K4.5 for further use.

2.2. Preparations of Buffers. Buffers were prepared with different levels of sodium $\left(\mathrm{Na}^{+}\right)$and potassium $\left(\mathrm{K}^{+}\right)$with a total amount of $145.4 \mathrm{mmol} / \mathrm{l}(\mathrm{mM})$. Buffers were labeled according to their $\mathrm{K}^{+}$concentration; for example, buffer $\mathrm{K} 4.5$ contains $4.5 \mathrm{mM} \mathrm{K}{ }^{+}$and $140.9 \mathrm{mM} \mathrm{Na}^{+}$. Furthermore, buffers contained $1 \mathrm{mM} \mathrm{MgCl}, 1 \mathrm{mM} \mathrm{CaCl}_{2}, 5 \mathrm{mM}$ glucose, and $10 \mathrm{mM}$ HEPES. Finally, buffers were adjusted to a $\mathrm{pH}$ of 7.4 unless indicated otherwise. Preparations were controlled by a blood gas analysis device (model ABL 700, Radiometer $\mathrm{GmbH}$, Willich, Germany) and an osmometer (Fa Gonotec, Berlin, Germany).

2.3. Measurement of Membrane Potential. Isolated PMN were incubated with $40 \mu \mathrm{M}$ bis(1,3-dibutylbarbituric acid) trimethine oxonol $\left(\mathrm{DiBAC}_{4}(3)\right)$ for $10 \mathrm{~min}$ for measuring the membrane potential. The Goldman-Hodgkin-Katz (GHK) equation $[37,38]$ was used in a simplified version to approximate the cellular membrane potential (Supplement 1 Equation 1). Intracellular $\mathrm{Na}^{+}$and $\mathrm{K}^{+}$levels were assumed to be $14 \mathrm{mM}$ and $140 \mathrm{mM}$. Relative transmembrane permeability (P) was assumed to be $5: 95$ for $\mathrm{Na}^{+}: \mathrm{K}^{+}$. As other ions remained constant in the buffers, they were not taken into account. In total, for K4.5 buffer, membrane potential was calculated to be $-65.4 \mathrm{mV}(\mathrm{K} 15=-49.3 \mathrm{mV})$. The resulting slope (Supplement 1 Equation 2) was used to quantify the 


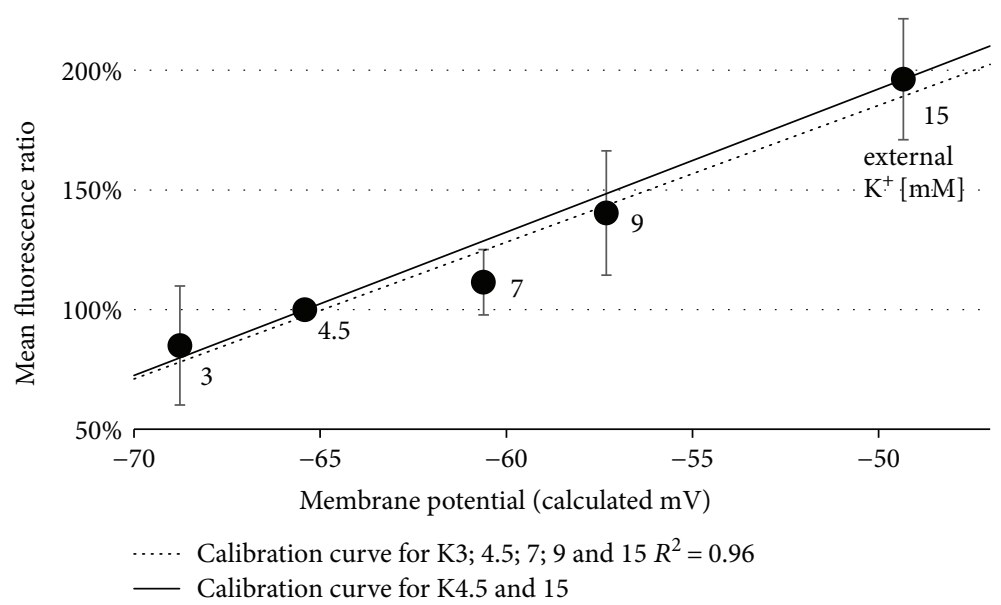

FIGURE 1: Calibration curves for alterations in the mean fluorescence depending on the calculated membrane potential. Shown here are the linear regression curves for two (solid line) or five different potassium concentrations (dotted line). $4.5 \mathrm{mM}$ potassium was considered the physiological extracellular concentration and set to $100 \%$. The method allows the detection of small alterations in membrane potential with an increase in the fluorescence of $6.0 \%$ (solid line) or $5.7 \%$ (dotted line) per $\mathrm{mV}$ increase in membrane potential. $N=5$ per concentration.

amount of change in membrane potential (Supplement 1 Equation 3). To enhance the reliability of the results, a control (Ctrl) for each probe and time point with K4.5 buffer and depolarized cells with K15 buffer was measured (Figure 1). All values are presented as changes in membrane potential compared to control cells, as absolute values of membrane potential could not be obtained reliably and are based on the described calculations.

2.4. Measurement of Intracellular $\mathrm{pH}$. Isolated PMN were preloaded with $1 \mu \mathrm{M}$ seminaphtharhodafluor (SNARF) for $20 \mathrm{~min}$ for measuring the intracellular $\mathrm{pH}$. Cells were washed once before measurement. Internal $\mathrm{pH}$ was determined using a standard curve applying nigericin as indicated by the manufacturer and described previously [14]. In experiments, where membrane potential and internal $\mathrm{pH}$ were synchronically assessed, SNARF was added for $20 \mathrm{~min}$ following $10 \mathrm{~min}$ of incubation with $\operatorname{DiBAC}_{4}(3)$.

2.5. Measurement of Mitochondrial Membrane Potential. To determine the mitochondrial membrane potential, PMN were

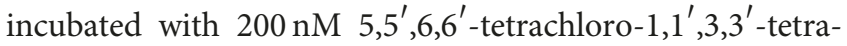
ethyl-imidacarbocyanine iodide (JC-1) for $30 \mathrm{~min}$. Mitochondrial membrane potential was compared with cells whose mitochondria were treated with the uncoupler carbonyl cyanide 3-chlorophenylhydrazone (CCCP) at $50 \mu \mathrm{M}$.

2.6. Stimulation of PMN and Flow Cytometry Analysis. Cells were stored in a darkened water bath at $37^{\circ} \mathrm{C}$ and incubated with the respective dye as described. Stimulants (e.g., human recombinant $\mathrm{C} 5 \mathrm{a}$, if not indicated otherwise in a concentration of $100 \mathrm{ng} / \mathrm{ml}$ ) were added directly after the dye incubation period. Usually, 10000 cells were measured per sample (5000 at least) using BD FACSCanto II (Franklin Lakes, USA) as flow cytometer. PMN cell population was analyzed by setting a proper gate using a side-scattered light area (SSC-A) and a forward-scattered light area (FSC-A) followed by a removal of duplets (usually $<2 \%$ ). In experiments with subgroup analysis of neutrophils, additional gates were applied to examine separately the 25\% PMN with the highest and the $25 \%$ with the lowest SSC/FSC values, respectively. Measurements of CD88 (C5aR1) were conducted after incubating cells with FITC-labeled anti-CD88 antibody for twenty minutes. The results are shown as mean fluorescence after subtraction of an appropriate isotype control.

2.7. Statistical Analyses. Statistical analyses were performed using GraphPad Prism 5 (GraphPad Software Inc., USA). The data were expressed as mean \pm standard deviation (SD). Outliers were identified and purged by using the $z$-score test. Gaussian distribution was determined by D'AgostinoPearson omnibus normality test. In case of a two-group comparison, the unpaired $t$-test for normal distribution and the Mann-Whitney $U$ test for non-Gaussian distribution were applied. If comparison versus zero was of interest, the $t$-sample $t$-test (for normality) and the Wilcoxon signed-rank test (for nonnormality) were applied. For multiple comparisons, ANOVA with Tukey post hoc testing was used (normality) or Kruskal-Wallis analysis with Dunn's post hoc testing (nonnormality). The preset significance levels of $p<0.05,<0.01$, and $<0.001$ are shown by $*, * *$, and $* * *$, respectively. Stars without link to another group express significance versus zero or control.

\section{Results}

3.1. C5a Depolarizes PMN in a Concentration- and TimeDependent Manner. The described method was internally validated using different buffers (Figure 1). After stimulation with $\mathrm{C} 5 \mathrm{a}$ in various concentrations (conversion $100 \mathrm{ng} / \mathrm{ml} \approx 9.1 \mathrm{nM}$ ), PMN of healthy human donors responded with a significant shift in membrane potential towards depolarization (Figure 2(a)). The early C5a-induced depolarization declined within $10 \mathrm{~min}$ at both C5a concentrations, $100 \mathrm{ng} / \mathrm{ml}$ and $1000 \mathrm{ng} / \mathrm{ml}$ (Figure 2(b)). 


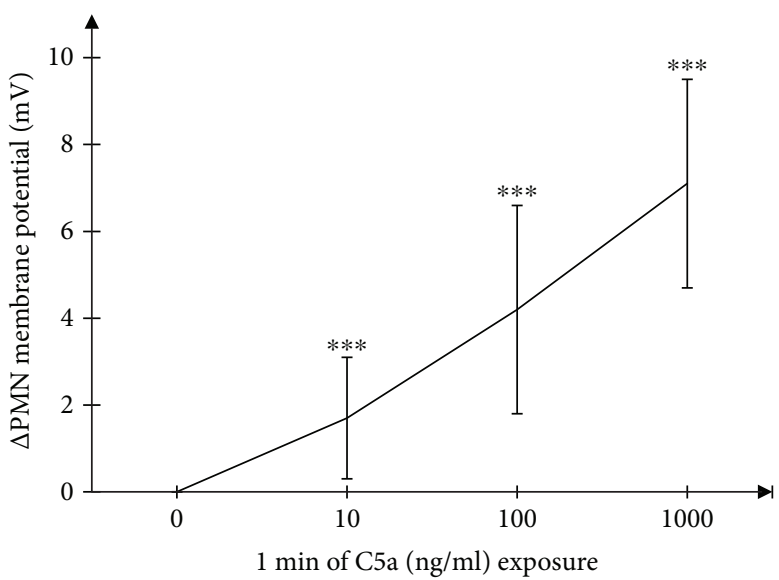

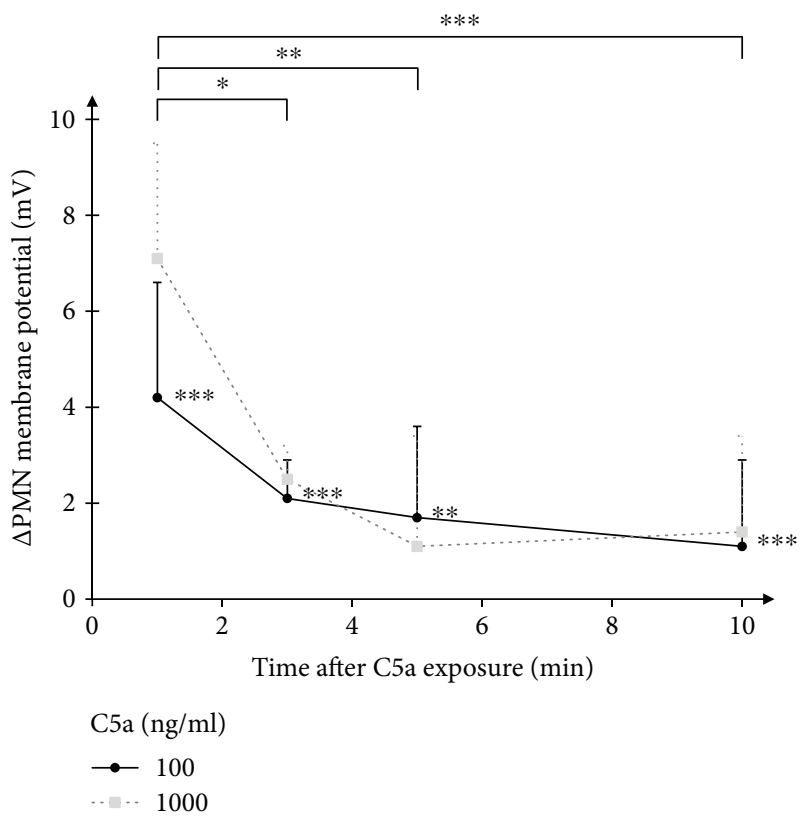

(b)

Figure 2: (a) Concentration dependency. Concentration-dependent change in resting membrane potential in human neutrophils after incubation with C5a demonstrating a depolarization in a dose-dependent manner $(n=11 ; 45 ; 6)$. (b) Time dependency. Time-dependent change of resting membrane potential of human PMN after stimulation with C5a $100 \mathrm{ng} / \mathrm{ml}$ (straight black line) and C5a $1000 \mathrm{ng} / \mathrm{ml}$ (gray dotted line), $n=3-45$. All significance indicators refer to C5a $100 \mathrm{ng} / \mathrm{ml} .{ }^{*} p<0.05,{ }^{* *} p<0.01$, and ${ }^{* * *} p<0.001$.

3.2. C5a Invokes a Change in Cell Shape Independent of Membrane Potential Changes. The chemoattractant C5a has an impact on cellular shape [39]. Therefore, FSC-A values as indicators for cell shape and SSC-A values as indicators for cellular granulation were monitored to investigate whether subgroups of PMN react differently and to exclude that the change in fluorescence intensity indicating depolarization was caused by changes in SSC and FSC recording. Cell shape as indicated by FSC-A increased in response to C5a $100 \mathrm{ng} / \mathrm{ml}$ by $39 \%$, while the depolarization by $\mathrm{K} 15$ was not able to provoke a similar response (Figures 3(a) and 3(b)). Subgroups of PMN (upper versus lower 25\% according to FSC-A measurements) did not show a potential difference to control cells. However, after stimulation with $\mathrm{C} 5 \mathrm{a}$, cells with higher FSC-A value exposed a significantly stronger fluorescence signal indicating an increased shift in membrane potential (Figure 3(c)). C5a also mediated a change in cellular granularity, resulting in a small but significant decrease by $7 \%$ in SSC-A. Again, this effect could not be observed when using potassium to depolarize the cells (Figure 3(d)). Nonetheless, cells with higher granularity expressed increased fluorescence intensity. This effect was augmented by C5a stimulation. In addition, a "forced" depolarization applying higher extracellular potassium concentrations did not explain the changes in fluorescence intensity, suggesting that the used dye was not (SSC) or only marginally (FSC) effected by cell shape changes (Figure 3(e)). Control cells, stimulated PMN with C5a $100 \mathrm{ng} / \mathrm{ml}$, and depolarized PMN remained in one population (Figure 3(f)). Therefore, a shift in mean fluorescence of stimulated PMN is mediated by a fluorescence increase in general, not by an extreme shift of a minor subgroup.

3.3. Interaction of the Cellular Membrane Potential with the Internal and External pH. A change in cellular membrane potential and external $\mathrm{pH}$ represents a major impact on the driving force of protons. Therefore, we investigated whether a change in membrane potential and external $\mathrm{pH}$ subsequently influences intracellular $\mathrm{pH}$. There was some evidence of an interconnection between the intracellular and extracellular $\mathrm{pH}$. However, there was no significant difference comparing control cells with depolarized cells by K15 (Figure $4(\mathrm{a})$ ).

Inflammatory processes are often accompanied by extracellular acidification of the (micro)environment. As depicted in Figure 4(b), the initial response of the membrane potential of human PMN to C5a significantly increased with decreased external $\mathrm{pH}$ values. However, after $10 \mathrm{~min}$, the response of the membrane potential returned to values of unstimulated cells (data not shown).

\subsection{Mitochondrial Membrane Potential Appears Resistant} against C5a Exposure. To further evaluate electrophysiological features of PMN and to determine whether C5ainduced delay in apoptosis during systemic inflammatory conditions (such as during shock) [40] is linked to changes in mitochondrial membrane potential, its reaction towards C5a exposure was investigated. Mitochondrial membrane potential was responsive to uncoupling. However, there was no significant alteration of the mitochondrial membrane 

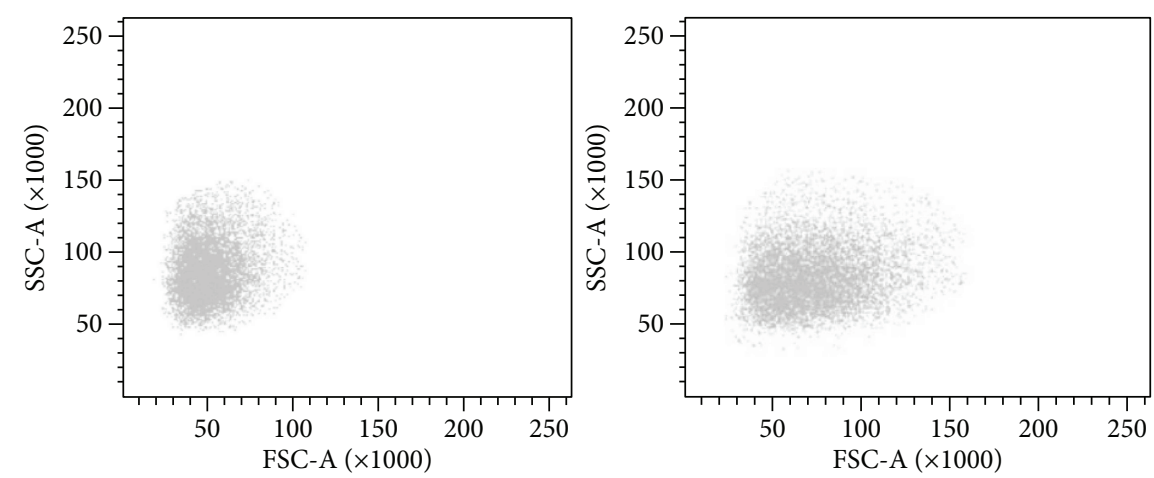

(a)

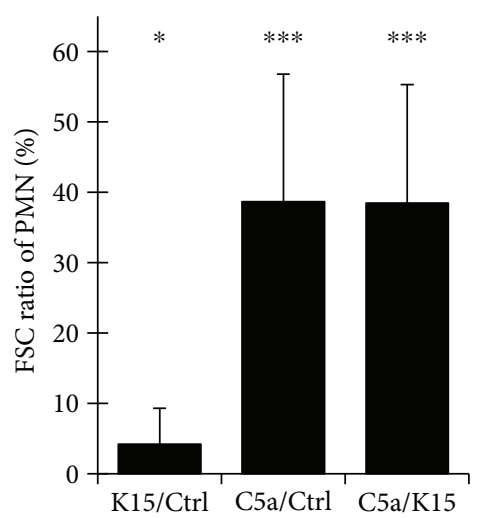

(b)

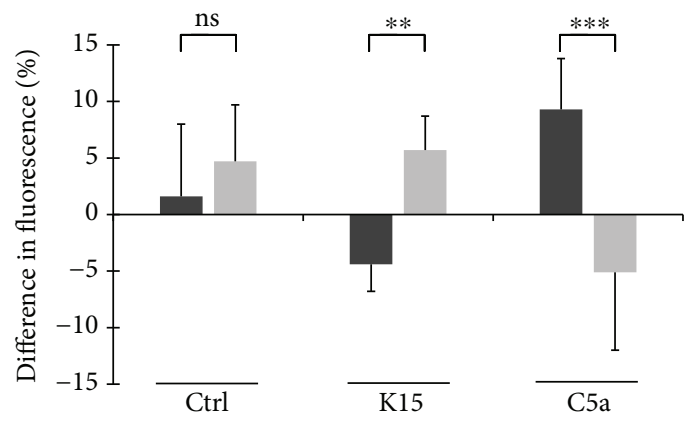

Subpopulation

- Upper FSC versus mean

Lower FSC versus mean

(c)

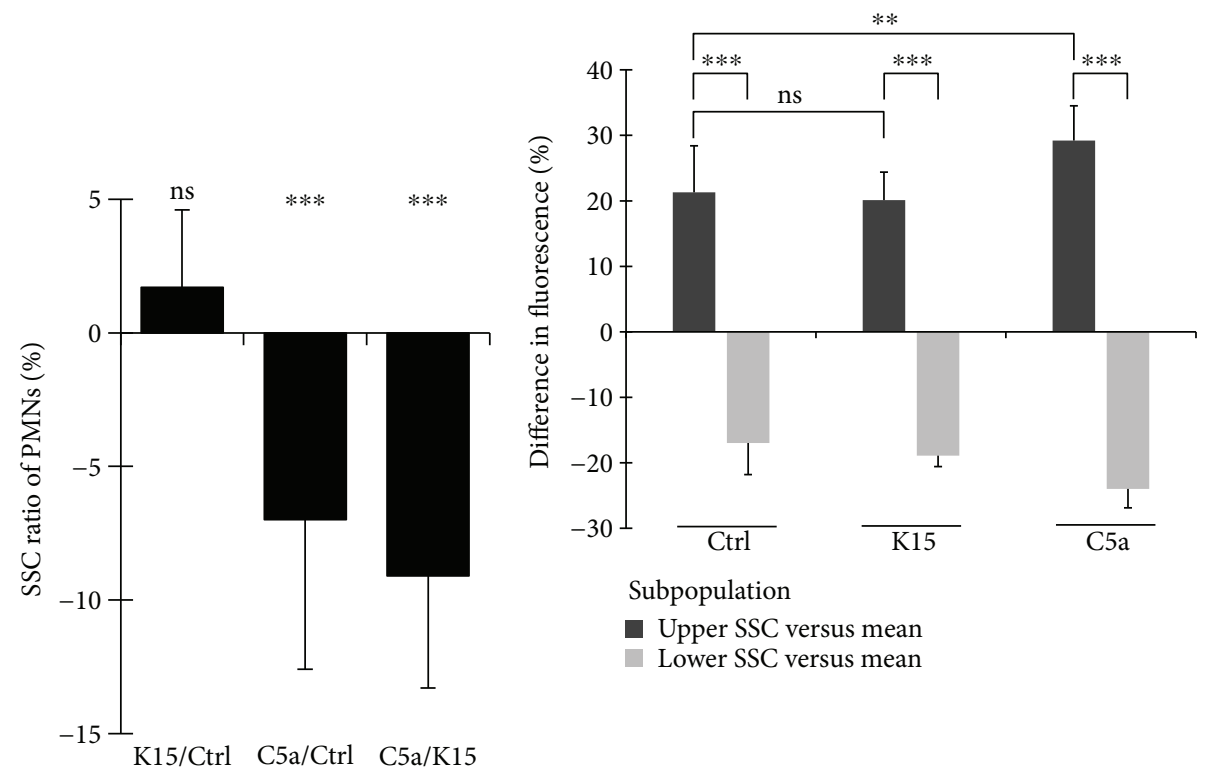

(d)

(e)

Figure 3: Continued. 


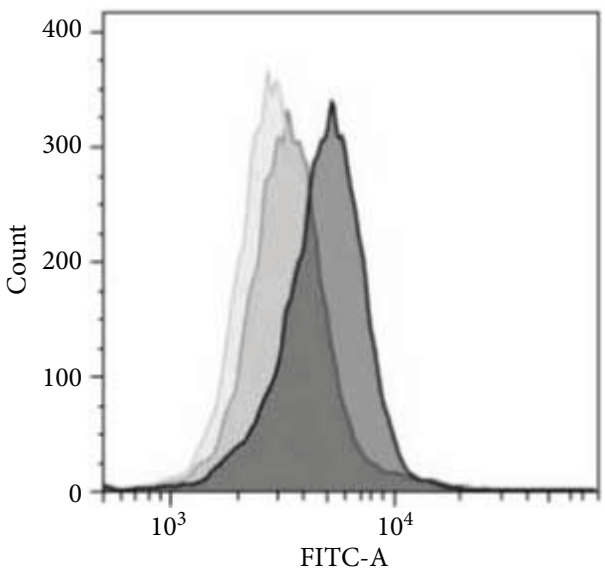

(f)

FIgURE 3: (a) Change in the shape and granularity of PMN after C5a stimulation. Influence of 1 minute C5a $100 \mathrm{ng} / \mathrm{ml}$ exposure on SSC-A (indicator for granularity) and FSC-A (indicator for changes in cell shape) on human PMN. (b) C5a-induced change in cell shape cannot be achieved by forced depolarization. Change in FSC-A for human PMN $(n=10-12)$ after incubation with 10 minutes in buffers plus 1 minute of C5a $100 \mathrm{ng} / \mathrm{ml}$. (c) Independency of cell shape from membrane potential. Difference of membrane potential in human PMN subgroups $(n=10-12)$. Shown is the relation between the $25 \%$ upper and lower part of cells in relation to the average fluorescence. (d) C5a-induced change in cell granularity cannot be achieved by forced depolarization. Change in SSC-A for human PMN $(n=10-12)$ after incubation with 10 minutes in buffer plus 1 minute of C5a $100 \mathrm{ng} / \mathrm{ml}$ exposure $=11$ minutes in total. (e) Independency of cell granularity from membrane potential. Difference of membrane potential in human PMN subgroups $(n=10-12)$. Shown is the relation between the $25 \%$ upper and lower part of cells in relation to the average fluorescence. (f) Representative illustration of determination of membrane potential. $\mathrm{DiBAC}_{4}(3)$ 's fluorescence was measured in the FITC channel. Each sample consists of Ctrl (PMN in K4.5=light gray), PMN exposed to C5a $100 \mathrm{ng} / \mathrm{ml}$ in K4.5 for one minute (gray), and PMN incubated in K15 (dark gray). ${ }^{*} p<0.05,{ }^{* *} p<0.01$, and ${ }^{* * *} p<0.001$.

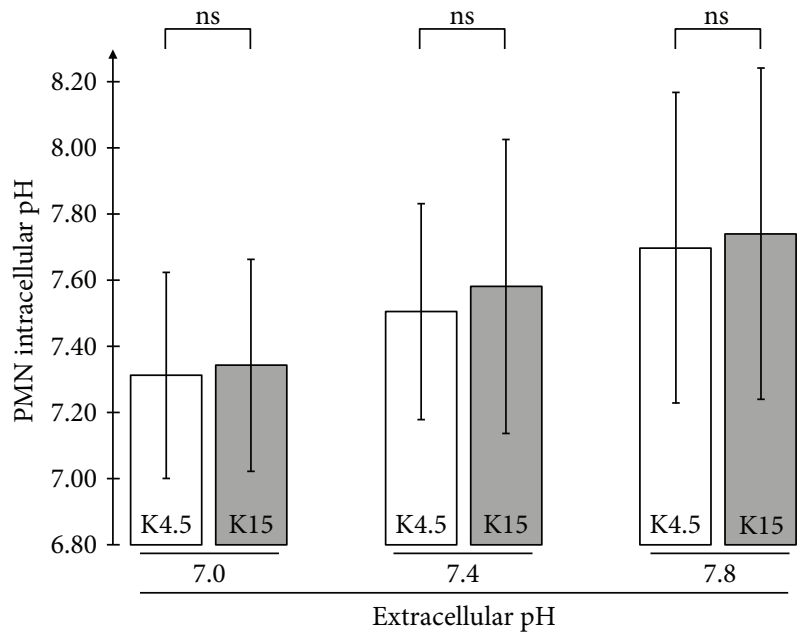

(a)

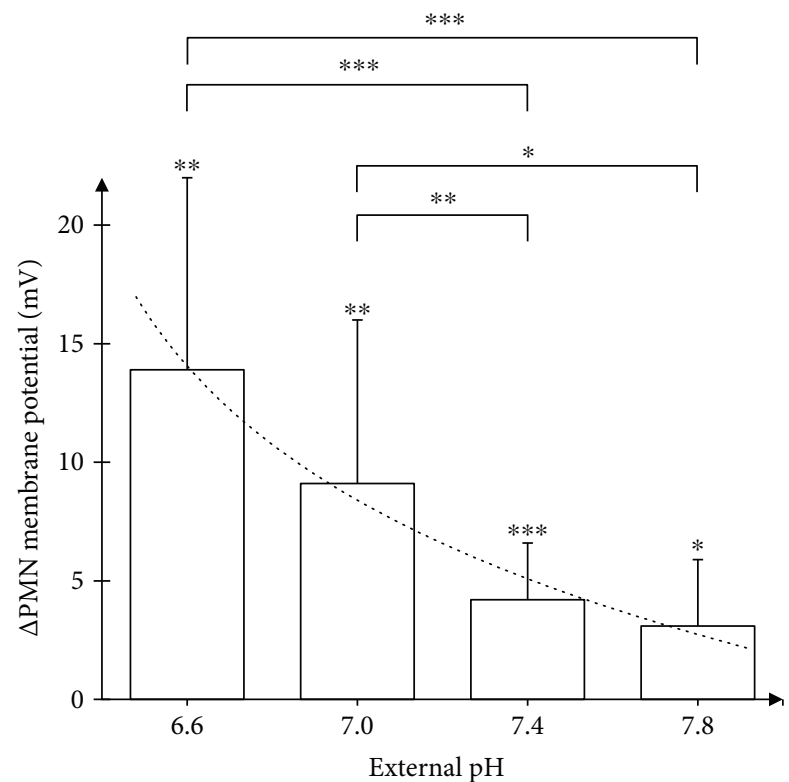

(b)

Figure 4: (a) Independency of intracellular $\mathrm{pH}$ from forced depolarization. PMN with different external pH, each with $\mathrm{K} 4.5$ (gray column) and K15 (white column) after a 10-minute incubation $(n=5)$. (b) Dependency of extracellular pH and response to C5a. Comparison of different external $\mathrm{pH}$ influence on the change of membrane potential of human PMN after stimulation with C5a $100 \mathrm{ng} / \mathrm{ml}$ after $1 \mathrm{minute}$; $n=8 ; 10 ; 45 ; 9$. The dotted line represents a logarithmic trend line $\left(R^{2}=0.98\right) .{ }^{*} p<0.05,{ }^{* *} p<0.01$, and ${ }^{* * *} p<0.001$. 


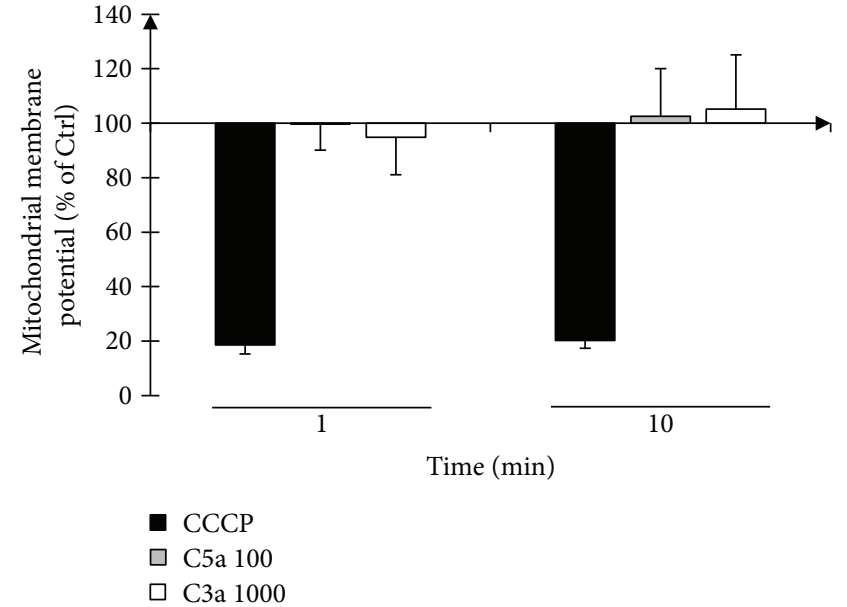

(a)

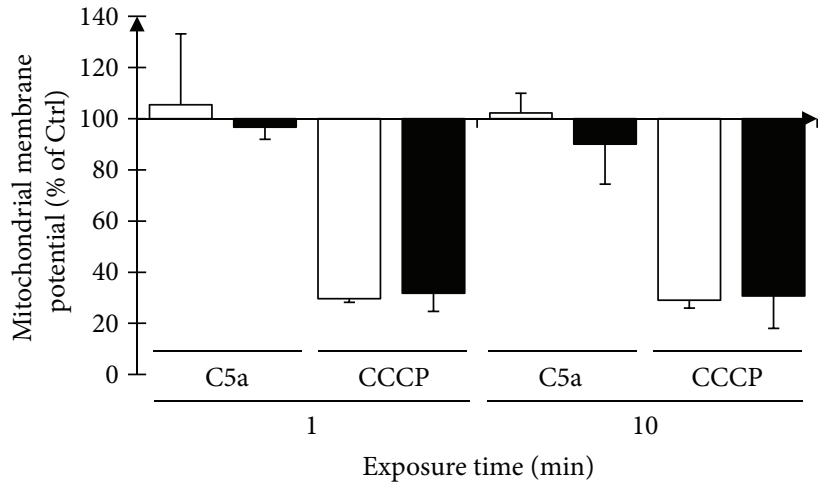

Hemorrhagic shock

$\square$ Pre

- Post

FIgURe 5: (a) Measurement of mitochondrial membrane potential of human PMN. No significant change in mitochondrial membrane potential occurred when human PMN are stimulated with C5a or C3a. In contrast, the potent uncoupler CCCP can effectively alter the mitochondrial membrane potential $(n=6 ; 5 ; 4)$. (b) Mitochondrial membrane potential before and after hemorrhagic shock. While C5a does not alter the mitochondrial membrane potential, the breakdown conjured by CCCP remains nearly the same $(n=3-4)$.

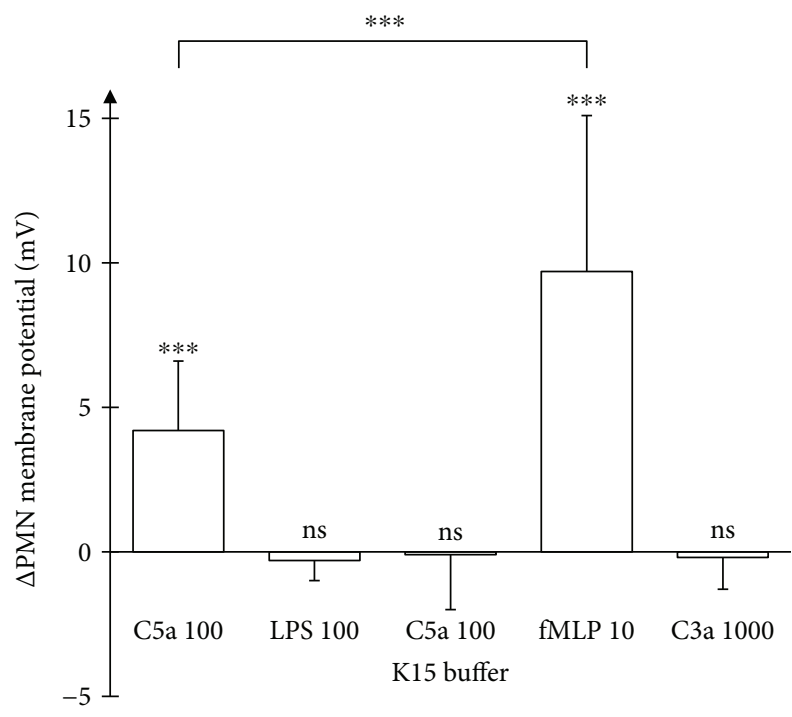

(a)

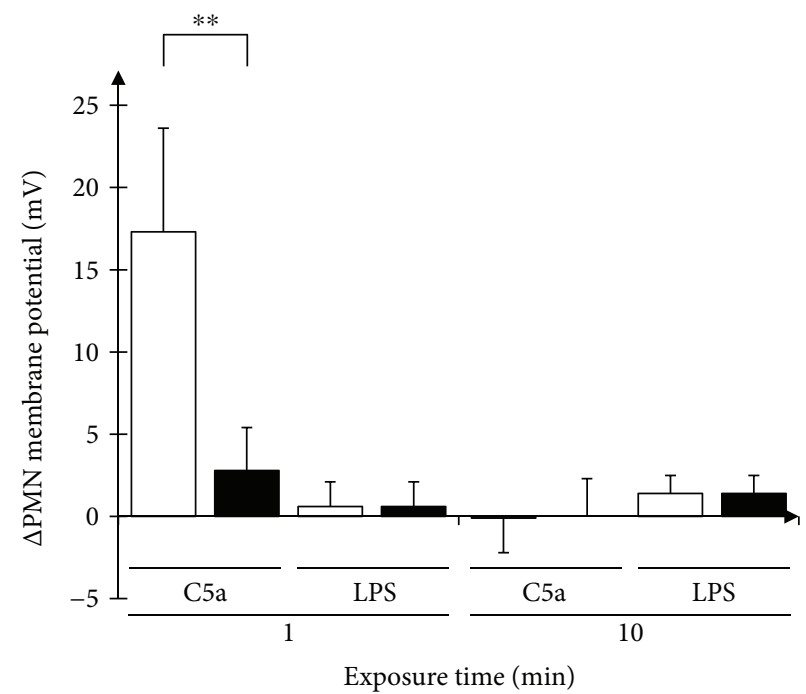

Hemorrhagic shock

$\square$ Pre

- Post

(b) 
TABLE 1: Expression of CD88 on human PMN.

\begin{tabular}{lccc}
\hline CD88 & Mean & SD & \\
\hline Upper SSC & $0.0 \%$ & $4.5 \%$ & $\mathrm{~ns}$ \\
Lower SSC & $-3.5 \%$ & $4.3 \%$ & \\
Upper FSC & $9.5 \%$ & $4.0 \%$ & $* *$ \\
Lower FSC & $-9.1 \%$ & $5.2 \%$ & \\
K15 versus Ctrl & $-5.9 \%$ & $5.3 \%$ & $\mathrm{~ns}$ \\
\hline
\end{tabular}

Expression of CD88 after a 20-minute incubation with an antibody in Ctrl, respectively, K15 buffer. Upper and lower SSC/FSC demonstrate the dependency of C5aR expression of FSC, but not SSC (25\% PMN each, $n=5)$. ${ }^{* *} p<0.01$.

response than $\mathrm{C} 5 \mathrm{a}$ in altering the membrane potential. As for stimulation with C5a (Figure 3(f)), PMN depolarization distributed almost homogenously among the cells and was not driven by an extreme depolarization of certain subgroups (data not shown).

3.6. Predepolarization Abolishes the C5a-Caused Membrane Potential Alterations. As a next step, we tested whether a prior depolarization influences the reaction of PMN to C5a. PMN suspended in K15 thus being depolarized by $\sim 15 \mathrm{mV}$ for $10 \mathrm{~min}$ showed no reaction to $\mathrm{C} 5 \mathrm{a}$ after $1 \mathrm{~min}$ in stark contrast to normal cells (Figure 6(a)). We therefore examined whether a depolarization by K15 leads to a change in C5aR1 expression, as assessed by flow cytometry $20 \mathrm{~min}$ after $\mathrm{C} 5 \mathrm{a}$ exposure. In this setting, no significant effect on C5aR1 (=CD88) surface expression could be detected (Table 1).

3.7. Breakdown of Membrane Potential Response to C5a in Hemorrhagic Shock. After characterization of the response in healthy subjects, we aimed to investigate the change under severe pathophysiological conditions. We chose a model of pig hemorrhagic shock and compared the response of porcine PMN to C5a and LPS. Prior to hemorrhage, porcine PMN responded to $\mathrm{C} 5 \mathrm{a}$ in a markedly stronger fashion than did human PMN (Figure 6(b)). However, this response was markedly reduced at the end of the shock period. The time-course of the membrane potential in response to $\mathrm{C} 5 \mathrm{a}$ was roughly comparable to the human conditions. Of note, the membrane potential of PMN did not feature a response to LPS neither pre- nor post-hemorrhagic shock. There was no change in potassium in the plasma samples of the animals (Table 2) and, as a consequence, no change in the calculated resting membrane potential prior and past hemorrhagic shock. However, the blood was diluted to some extent as indicated by the values of hemoglobin. C5a plasma preshock concentrations $(10.3 \pm 3.3 \mathrm{ng} / \mathrm{ml})$ were similar to post-shock concentrations $(10.5 \pm 0.9 \mathrm{ng} / \mathrm{ml})$ excluding a principal receptor downregulation by excessive C5a. At last, we assessed whether there were any endotoxins present in the circulation pre- or posthemorrhagic shock. However, endotoxin concentrations were below the detection limit in all samples (data not shown), excluding LPS preexposure effects.

\section{Discussion}

4.1. Overview. Significant depolarization of the membrane potential of PMN could be found in a dose-dependent manner after one minute of C5a exposure. C5a in concentrations between 100 and $1000 \mathrm{ng} / \mathrm{ml}$ induced a transient depolarization that decreased markedly until ten minutes. The applied method allowed generation of precise calibration curves between one and ten minutes. Therefore, we might have missed very early and late changes in membrane potential differences, for example, a theoretical early higher maximum at C5a $1000 \mathrm{ng} / \mathrm{ml}$. The used C5a concentrations may be considered within the range of (patho)physiological concentrations (EC50 C5a on C5aR1 $\approx 11 \mathrm{ng} / \mathrm{ml}$ ) [5]. C5a concentration varies in physiological conditions around $0-20 \mathrm{ng} / \mathrm{ml}(110 \mathrm{ng} / \mathrm{ml}$ in one report), increasing to $100-1000 \mathrm{ng} / \mathrm{ml}$ in sepsis, and was reported to reach up to $3100 \mathrm{ng} / \mathrm{ml}$ after activation with cobra venom factor $[5,6,41,42]$. Here, we suggest that the electrophysiological consequences of PMN membrane potential may depend on different C5a concentrations. While it was not within the scope of the present study to determine the responsible ion flux, it might be linked to activation of NADPH oxidase $[27,28,30]$ and/or a change in potassium conductance, as PMN possess several potassium channels [31]. The major role of potassium conductance for transmembrane potential in human PMN is supported by studies using other fluorescence dyes in the presence or absence of the $\mathrm{K}^{+}$ ionophore valinomycin $[9,43,44]$.

Analyzing subgroups of PMN, we demonstrated that C5a changes cell shape (Figure 3(a)) and leads to a more pronounced transmembrane depolarization in larger cells as characterized via higher FSC-A values. Forced depolarization did not trigger reduction in cellular granularity. However, C5a reduced the level of granularity, and cells with higher granularity emitted in the resting as well as in stimulated state a higher level of fluorescence indicating a more positive transmembrane potential. Of interest, we did not have any hint that degranulation does result in significant loss of dye. Even if this is the case, we might have slightly underestimated the change in membrane potential, as an increase in fluorescence indicates depolarization. While we cannot completely exclude that this is due to a specific dye characteristic, the different levels of granularity likely represent PMN of different age.

Surprisingly, forced depolarization by extracellular K15 had no effect on intracellular $\mathrm{pH}$. Theoretically, the inward proton-driving force should be reduced by a positive shift in the cellular membrane potential (Figure 4(a)). It is tempting to speculate that resting PMN have only a small conductance for protons or that intracellular $\mathrm{pH}$ is balanced. In addition, the early transmembrane potential response to C5a was enhanced in external acidification conditions that occur during excessive inflammation and are known to promote MODS. Interestingly, another study using PMA to stimulate neutrophils described reduced depolarization at external $\mathrm{pH}$ values of 6.6 [17], possibly due to different compensation mechanisms depending on the initial stimulus.

In a translational model of porcine hemorrhage, shock led to neutrophil unresponsiveness to C5a. As neutrophil 
TABLE 2: Results of blood gas analyses of porcine hemorrhagic shock trial.

\begin{tabular}{|c|c|c|c|c|c|c|}
\hline & & \multicolumn{2}{|c|}{ Preshock } & \multicolumn{2}{|c|}{ Postshock } & \multirow{2}{*}{$\begin{array}{l}\text { Change } \\
\text { Post/pre }\end{array}$} \\
\hline & & Mean & SD & Mean & SD & \\
\hline Calculated membrane potential & $\mathbf{m v}$ & -68.24 & 0.60 & -66.53 & 1.60 & $-3 \%$ \\
\hline Leukocytes & $/ \mu l$ & 11511 & 3655 & 19892 & 5571 & $75 \%$ \\
\hline $\mathrm{K}^{+}$ & $\mathrm{mM}$ & 3.30 & 0.22 & 4.06 & 0.88 & $23 \%$ \\
\hline $\mathrm{Na}^{+}$ & $\mathrm{mM}$ & 140.80 & 0.45 & 140.20 & 3.56 & $0 \%$ \\
\hline $\mathrm{Ca}^{++}$ & $\mathrm{mM}$ & 0.71 & 0.23 & 0.69 & 0.17 & $14 \%$ \\
\hline $\mathrm{Cl}^{-}$ & $\mathrm{mM}$ & 95.20 & 2.86 & 98.80 & 0.84 & $4 \%$ \\
\hline Anion gap & $\mathrm{mM}$ & 26.76 & 3.12 & 25.70 & 2.25 & $-3 \%$ \\
\hline $\mathrm{pH}$ & & 7.38 & 0.04 & 7.37 & 0.05 & $0 \%$ \\
\hline $\mathrm{pCO}_{2}$ & $\mathrm{mmHg}$ & 39.54 & 4.46 & 35.42 & 4.69 & $-9 \%$ \\
\hline $\mathrm{pO}_{2}$ & $\mathrm{mmHg}$ & 118.00 & 14.73 & 85.20 & 13.70 & $-26 \%$ \\
\hline $\mathrm{hb}$ & $\mathrm{g} / \mathrm{dl}$ & 7.28 & 0.49 & 12.16 & 3.23 & $69 \%$ \\
\hline hct & $\%$ & 22.80 & 1.48 & 37.34 & 9.83 & $66 \%$ \\
\hline $\mathrm{sO}_{2}$ & $\%$ & 99.04 & 0.75 & 95.14 & 2.71 & $-4 \%$ \\
\hline Glucose & $\mathrm{mg} / \mathrm{dl}$ & 94.80 & 10.80 & 88.80 & 18.59 & $-7 \%$ \\
\hline Lactate & $\mathrm{mM}$ & 1.76 & 0.77 & 3.42 & 1.60 & $107 \%$ \\
\hline Thrombocytes & $/ \mu l$ & 240800 & 71304 & 184600 & 60444 & $-23 \%$ \\
\hline
\end{tabular}

Hemorrhagic shock $(n=5)$ did not have a strong impact on calculated membrane potential, external ion concentration, and $\mathrm{pH}$.

activation during the shock period cannot be excluded, the impaired response of neutrophils towards C5a underlines the role of an altered response of transmembrane potential as part of the pathophysiological reaction of PMN in severe inflammation. Although human recombinant C5a was used to stimulate porcine PMN, it is chemically similar to porcine C5a [5] and was capable to evoke a significant membrane potential response prior to hemorrhagic shock, which was more pronounced than in the human in vitro setting.

4.2. Strengths of the Study. We established and validated a reliable method for PMN to detect even small changes in transmembrane potential towards hyper- or depolarization (Figure 1), which has been previously described for other cell types and controlled by patch-clamp technique [38, 45]. As the slope of the calibration curve remained stable over a certain range of $\mathrm{mV}$, we assume that equilibration of membrane potential to the altered ion concentrations happens at least to a considerable extent as calculated by the GHK equation. Even if this would only reflect a part of the reality, the measured changes in membrane potential remain rather underestimated (see also Limitations of the Study) as studies using PMA reported a higher delta in membrane potential [11]. However, the smaller change in membrane potential could also be due to compensation mechanisms specific to our stimulus C5a. By using fMLP at a concentration of $10 \mu \mathrm{M}$ (which is reported to induce a maximal chemotactic response in neutrophils [46]), we demonstrated that the method is principally able to detect larger changes in membrane potential than evoked by C5a.

By using flow cytometry, we could avoid phagocytic triggering of the PMN by exposing the cells to devices such as patch-clamp electrodes. Furthermore, we avoided alteration in intracellular ion concentration and most importantly preserved cellular membrane integrity. Moreover, the applied method allowed measurement of thousands of cells per subject within seconds and supported the main finding (C5a-induced depolarization) by a high number ( $n=45$ for one minute of stimulation with C5a $100 \mathrm{ng} / \mathrm{ml}$ ) of subjects. In addition, we demonstrated that our approach is not compromised by changes in cell shape or granularity (Figures 3(b)-3(e)). The method has proved to be applicable for translational studies, as it could define alterations of the transmembrane potential in a highly standardized and clinically most relevant hemorrhagic shock model.

4.3. Limitations of the Study. Measuring membrane potential by flow cytometry may have three downsides: First, the time resolution is limited, especially in comparison to patchclamp techniques. We decided to start measuring after one minute of stimulation in order to enhance standardization and controllability of experiments. In addition, the method is limited by the properties of the used dye. The dye and/or the time resolution (and the issues discussed below regarding temperature) might be the reason why the results of this work differ quantitatively from other groups [9, 17, 47-49], as the reported results here are of lower magnitude. Second, membrane potential is proportionally linked to temperature, which is also represented within the GHK equation $[37,38]$. While (pre)incubating cells, we stored the specimens at $37^{\circ} \mathrm{C}$ in a water bath. However, as cells are sucked into the flow cytometer, changes in surrounding temperature as well as mixing with rinsing fluid of the system are inevitable. Nonetheless, as temperature and-according to the GHK equation [37, 38]-therefore membrane potential are decreased by this effect, we might have rather underestimated instead of overestimated the changes in membrane potential. Third, we cannot measure absolute values of 
membrane potential, as we have no intracellular detector. Thus, we had to make several assumptions about intracellular concentrations and transcellular permeability of sodium and potassium. However, as literature findings in general agree that potassium conductance is in resting PMN most relevant $[43,44]$ compared to sodium conductance, we might have slightly miscalculated the membrane potential in absolute values. However, our estimate of the resting membrane potential at $\mathrm{K} 4.5$ with $-65.4 \mathrm{mV}$ is within the range of previous studies, which used an ionophore in order to obtain absolute values $(-59 \mathrm{mV}$, with an additional hyperpolarization of $11 \mathrm{mV}$ after addition of valinomycin [44], $-73 \mathrm{mV}$ [50], and $-75 \mathrm{mV}$ [10] and a patch-clamp-based approximation of the resting membrane potential of -50 to $-60 \mathrm{mV}$ [31]). Nevertheless, as we measured a calibration curve for every sample at every time point, the calculated change in membrane potential remains robust. While detection of the underlying alterations in defined ion channels being involved was beyond the scope of the present investigation, the changes of the membrane potential (in $\mathrm{mV}$ ) validly reflects the overall alterations induced by the investigated conditions, irrespectively, whether it is invoked by sodium, potassium, or other ions. The following example not only demonstrates the limitation of the calculated values (Figure 1) but also strengthens the robustness of the measured change in membrane potential (Figure 2(a) and on): Assuming the conductance of sodium and potassium is 0.8 instead of 0.95 and 0.2 instead of 0.05 , respectively, the calculated membrane potential would be $-34.0 \mathrm{mV}$ for $\mathrm{K} 4.5$ and $-29.2 \mathrm{mV}$ for K15. However, the calculated change in membrane potential for stimulated PMN with one minute of C5a $100 \mathrm{ng} / \mathrm{ml}$ remains comparable $(3.0 \mathrm{mV}$ with 0.8 potassium conductance versus $4.2 \mathrm{mV}$ with 0.95 potassium conductance).

At last, we want to discuss the composition of the buffers. While most ions, glucose, $\mathrm{pH}$, and osmolality were tightly controlled and adjusted to achieve physiological levels, the buffers lacked bicarbonate and consisted of an unphysiologically high chloride concentration. We accepted this limitation as bicarbonate, and consequently, buffers' $\mathrm{pH}$ is unstable in open systems, preferring precise $\mathrm{pH}$ control over normochloride solutions.

\section{Conclusion and Outlook}

Changes in transmembrane potential were a hallmark of C5a and fMLP, but not of C3a or LPS stimulation. Extracellular acidification enhanced the response while predepolarization and alkalinization diminished the response. Hemorrhagic shock almost completely suppressed the $\mathrm{C} 5 \mathrm{a}$ response in membrane potential, which might represent a mechanism for development of neutrophil dysfunction in severe inflammation with coagulo- and complementopathy. Further research needs to verify these results preferentially with a different method and determine what extent of membrane potential change is helpful or harmful to PMN in order to exert their physiological functions.

In addition, exploration of the involved ion channels might reveal perpetrator ion channels that could be blocked to avoid development of immune incompetence of PMN and septic complications in shock.

\section{Conflicts of Interest}

The authors declare that they have no conflicts of interest.

\section{Supplementary Materials}

Supplement 1: equations 1-3 demonstrate the application of the GHK equation to calculate the change of membrane potential of PMN after stimulation. (Supplementary Materials)

\section{References}

[1] F. Morriello, "Neutrophils and inflammation: unraveling a new connection," Biology and Medicine, vol. 8, no. 6, 2016.

[2] E. Kolaczkowska and P. Kubes, "Neutrophil recruitment and function in health and inflammation," Nature Reviews Immunology, vol. 13, no. 3, pp. 159-175, 2013.

[3] M. Huber-Lang, F. Gebhard, C. Q. Schmidt, A. Palmer, S. Denk, and R. Wiegner, "Complement therapeutic strategies in trauma, hemorrhagic shock and systemic inflammation closing Pandora's box?," Seminars in Immunology, vol. 28, no. 3, pp. 278-284, 2016.

[4] P. H. C. Leliefeld, C. M. Wessels, L. P. H. Leenen, L. Koenderman, and J. Pillay, "The role of neutrophils in immune dysfunction during severe inflammation," Critical Care, vol. 20, no. 1, p. 73, 2016.

[5] A. Klos, E. Wende, K. J. Wareham, and P. N. Monk, "International Union of Basic and Clinical Pharmacology. LXXXVII. Complement peptide C5a, C4a, and C3a receptors," Pharmacological Reviews, vol. 65, no. 1, pp. 500-543, 2013.

[6] P. N. Monk, A.-M. Scola, P. Madala, and D. P. Fairlie, "Function, structure and therapeutic potential of complement C5a receptors," British Journal of Pharmacology, vol. 152, no. 4, pp. 429-448, 2007.

[7] N. Demaurex, A. Monod, D. P. Lew, and K. H. Krause, "Characterization of receptor-mediated and store-regulated $\mathrm{Ca}^{2+}$ influx in human neutrophils," Biochemical Journal, vol. 297, no. 3, pp. 595-601, 1994.

[8] F. Di Virgilio, P. D. Lew, T. Andersson, and T. Pozzan, "Plasma membrane potential modulates chemotactic peptide-stimulated cytosolic free $\mathrm{Ca}^{2+}$ changes in human neutrophils," The Journal of Biological Chemistry, vol. 262, no. 10, pp. 4574-4579, 1987.

[9] B. E. Seligmann and J. I. Gallin, "Use of lipophilic probes of membrane potential to assess human neutrophil activation. Abnormality in chronic granulomatous disease," The Journal of Clinical Investigation, vol. 66, no. 3, pp. 493-503, 1980.

[10] C. L. Bashford and C. A. Pasternak, "Plasma membrane potential of neutrophils generated by the $\mathrm{Na}^{+}$pump," Biochimica et Biophysica Acta (BBA) - Biomembranes, vol. 817, no. 1, pp. 174-180, 1985.

[11] A. Jankowski and S. Grinstein, "A noninvasive fluorimetric procedure for measurement of membrane potential. Quantification of the NADPH oxidase-induced depolarization in activated neutrophils," Journal of Biological Chemistry, vol. 274, no. 37, pp. 26098-26104, 1999. 
[12] S. Grinstein, W. Furuya, and W. D. Biggar, "Cytoplasmic pH regulation in normal and abnormal neutrophils. Role of superoxide generation and $\mathrm{Na}^{+} / \mathrm{H}^{+}$exchange," The Journal of Biological Chemistry, vol. 261, no. 2, pp. 512-514, 1986.

[13] L. Simchowitz, "Intracellular $\mathrm{pH}$ modulates the generation of superoxide radicals by human neutrophils," The Journal of Clinical Investigation, vol. 76, no. 3, pp. 1079-1089, 1985.

[14] S. Denk, M. D. Neher, D. A. C. Messerer et al., "Complement C5a functions as a master switch for the $\mathrm{pH}$ balance in neutrophils exerting fundamental immunometabolic effects," The Journal of Immunology, vol. 198, no. 12, pp. 4846-4854, 2017.

[15] K. Suszták, A. Mócsai, E. Ligeti, and A. Kapus, "Electrogenic $\mathrm{H}+$ pathway contributes to stimulus-induced changes of internal $\mathrm{pH}$ and membrane potential in intact neutrophils: role of cytoplasmic phospholipase A2," Biochemical Journal, vol. 325, no. 2, pp. 501-510, 1997.

[16] J. Schrenzel, L. Serrander, B. Bánfi et al., "Electron currents generated by the human phagocyte NADPH oxidase," Nature, vol. 392, no. 6677, pp. 734-737, 1998.

[17] L. M. Henderson, J. B. Chappell, and O. T. G. Jones, "The superoxide-generating NADPH oxidase of human neutrophils is electrogenic and associated with an $\mathrm{H}^{+}$channel," Biochemical Journal, vol. 246, no. 2, pp. 325-329, 1987.

[18] T. E. DeCoursey, D. Morgan, and V. V. Cherny, "The voltage dependence of NADPH oxidase reveals why phagocytes need proton channels," Nature, vol. 422, no. 6931, pp. 531-534, 2003.

[19] G. L. Petheő and N. Demaurex, "Voltage- and NADPHdependence of electron currents generated by the phagocytic NADPH oxidase," Biochemical Journal, vol. 388, no. 2, pp. 485-491, 2005.

[20] L. M. Henderson, J. B. Chappell, and O. T. G. Jones, "Internal $\mathrm{pH}$ changes associated with the activity of NADPH oxidase of human neutrophils. Further evidence for the presence of an $\mathrm{H}^{+}$ conducting channel," Biochemical Journal, vol. 251, no. 2, pp. 563-567, 1988.

[21] N. Demaurex, S. Grinstein, M. Jaconi, W. Schlegel, D. P. Lew, and K. H. Krause, "Proton currents in human granulocytes: regulation by membrane potential and intracellular $\mathrm{pH}$," The Journal of Physiology, vol. 466, pp. 329-344, 1993.

[22] L. M. Henderson, G. Banting, and J. B. Chappell, "The arachidonate-activable, NADPH oxidase-associated $\mathrm{H}^{+}$channel. Evidence that gp91-phox functions as an essential part of the channel," The Journal of Biological Chemistry, vol. 270, no. 11, pp. 5909-5916, 1995.

[23] T. E. DeCoursey, V. V. Cherny, W. Zhou, and L. L. Thomas, "Simultaneous activation of NADPH oxidase-related proton and electron currents in human neutrophils," Proceedings of the National Academy of Sciences, vol. 97, no. 12, pp. 68856889, 2000.

[24] G. L. Petheö, A. Maturana, A. Spät, and N. Demaurex, "Interactions between electron and proton currents in excised patches from human eosinophils," The Journal of General Physiology, vol. 122, no. 6, pp. 713-726, 2003.

[25] I. S. Ramsey, E. Ruchti, J. S. Kaczmarek, and D. E. Clapham, "Hv1 proton channels are required for high-level NADPH oxidase-dependent superoxide production during the phagocyte respiratory burst," Proceedings of the National Academy of Sciences, vol. 106, no. 18, pp. 7642-7647, 2009.

[26] D. Morgan, M. Capasso, B. Musset et al., "Voltage-gated proton channels maintain $\mathrm{pH}$ in human neutrophils during phagocytosis," Proceedings of the National Academy of Sciences, vol. 106, no. 42, pp. 18022-18027, 2009.

[27] A. El Chemaly, Y. Okochi, M. Sasaki, S. Arnaudeau, Y. Okamura, and N. Demaurex, "VSOP/Hv1 proton channels sustain calcium entry, neutrophil migration, and superoxide production by limiting cell depolarization and acidification," The Journal of Experimental Medicine, vol. 207, no. 1, pp. 129-139, 2010.

[28] L. C. McPhail and R. Snyderman, "Activation of the respiratory burst enzyme in human polymorphonuclear leukocytes by chemoattractants and other soluble stimuli. Evidence that the same oxidase is activated by different transductional mechanisms," The Journal of Clinical Investigation, vol. 72, no. 1, pp. 192-200, 1983.

[29] T. E. DeCoursey, "Interactions between NADPH oxidase and voltage-gated proton channels: why electron transport depends on proton transport," FEBS Letters, vol. 555, no. 1, pp. 57-61, 2003.

[30] T. E. DeCoursey, "The intimate and controversial relationship between voltage-gated proton channels and the phagocyte NADPH oxidase," Immunological Reviews, vol. 273, no. 1, pp. 194-218, 2016.

[31] K. H. Krause and M. J. Welsh, "Voltage-dependent and $\mathrm{Ca} 2(+)$-activated ion channels in human neutrophils," The Journal of Clinical Investigation, vol. 85, no. 2, pp. 491-498, 1990.

[32] M. Huber-Lang, V. J. Sarma, K. T. Lu et al., "Role of C5a in multiorgan failure during sepsis," The Journal of Immunology, vol. 166, no. 2, pp. 1193-1199, 2001.

[33] M. S. Huber-Lang, E. M. Younkin, J. V. Sarma et al., "Complement-induced impairment of innate immunity during sepsis," The Journal of Immunology, vol. 169, no. 6, pp. 3223-3231, 2002.

[34] E. Knöller, T. Stenzel, F. Broeskamp et al., "Effects of hyperoxia and mild therapeutic hypothermia during resuscitation from porcine hemorrhagic shock," Critical Care Medicine, vol. 44, no. 5, pp. e264-e277, 2016.

[35] B. L. Nussbaum, T. Stenzel, T. Merz et al., "Hyperoxia or therapeutic hypothermia during resuscitation from non-lethal hemorrhagic shock in swine," Shock, vol. 48, no. 5, pp. 564570, 2017.

[36] Y.-M. Yao, H. Redl, S. Bahrami, and G. Schlag, "The inflammatory basis of trauma/shock-associated multiple organ failure," Inflammation Research, vol. 47, no. 5, pp. 201-210, 1998.

[37] D. E. Goldman, "Potential, impedance, and rectification in membranes," The Journal of General Physiology, vol. 27, no. 1, pp. 37-60, 1943.

[38] T. Klapperstück, D. Glanz, S. Hanitsch, M. Klapperstück, F. Markwardt, and J. Wohlrab, "Calibration procedures for the quantitative determination of membrane potential in human cells using anionic dyes," Cytometry Part A, vol. 83A, no. 7, pp. 612-626, 2013.

[39] S. Denk, R. P. Taylor, R. Wiegner et al., "Complement C5ainduced changes in neutrophil morphology during inflammation," Scandinavian Journal of Immunology, vol. 86, no. 3, pp. 143-155, 2017.

[40] M. C. Perianayagam, V. S. Balakrishnan, A. J. King, B. J. G. Pereira, and B. L. Jaber, "C5a delays apoptosis of human neutrophils by a phosphatidylinositol 3-kinase-signaling pathway," Kidney International, vol. 61, no. 2, pp. 456463, 2002. 
[41] J. S. Solomkin, M. K. Jenkins, R. D. Nelson, D. Chenoweth, and R. L. Simmons, "Neutrophil dysfunction in sepsis. II. Evidence for the role of complement activation products in cellular deactivation," Surgery, vol. 90, no. 2, pp. 319-327, 1981.

[42] P. A. Ward, "The dark side of C5a in sepsis," Nature Reviews Immunology, vol. 4, no. 2, pp. 133-142, 2004.

[43] G. S. Jones, K. Van Dyke, and V. Castranova, "Purification of human granulocytes by centrifugal elutriation and measurement of transmembrane potential," Journal of Cellular Physiology, vol. 104, no. 3, pp. 425-431, 1980.

[44] L. Simchowitz, I. Spilberg, and P. De Weer, "Sodium and potassium fluxes and membrane potential of human neutrophils: evidence for an electrogenic sodium pump," The Journal of General Physiology, vol. 79, no. 3, pp. 453-479, 1982.

[45] T. Klapperstück, D. Glanz, M. Klapperstück, and J. Wohlrab, "Methodological aspects of measuring absolute values of membrane potential in human cells by flow cytometry," Cytometry Part A, vol. 75A, no. 7, pp. 593-608, 2009.

[46] M. S. Huber-Lang, J. V. Sarma, S. R. McGuire et al., "Structurefunction relationships of human C5a and C5aR," The Journal of Immunology, vol. 170, no. 12, pp. 6115-6124, 2003.

[47] B. Bánfi, J. Schrenzel, O. Nüsse et al., "A novel $\mathrm{H}^{+}$conductance in eosinophils," The Journal of Experimental Medicine, vol. 190, no. 2, pp. 183-194, 1999.

[48] B. E. Seligmann, E. K. Gallin, D. L. Martin, W. Shain, and J. I. Gallin, "Interaction of chemotactic factors with human polymorphonuclear leukocytes: studies using a membrane potential-sensitive cyanine dye," The Journal of Membrane Biology, vol. 52, no. 3, pp. 257-272, 1980.

[49] B. Seligmann, T. M. Chused, and J. I. Gallin, "Human neutrophil heterogeneity identified using flow microfluorometry to monitor membrane potential," The Journal of Clinical Investigation, vol. 68, no. 5, pp. 1125-1131, 1981.

[50] M. A. Martin, W. M. Nauseef, and R. A. Clark, "Depolarization blunts the oxidative burst of human neutrophils. Parallel effects of monoclonal antibodies, depolarizing buffers, and glycolytic inhibitors," The Journal of Immunology, vol. 140, no. 11, pp. 3928-3935, 1988. 


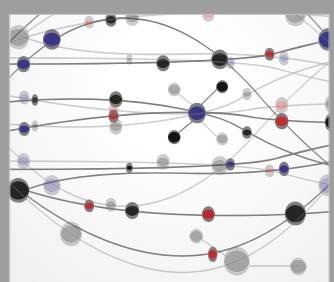

The Scientific World Journal
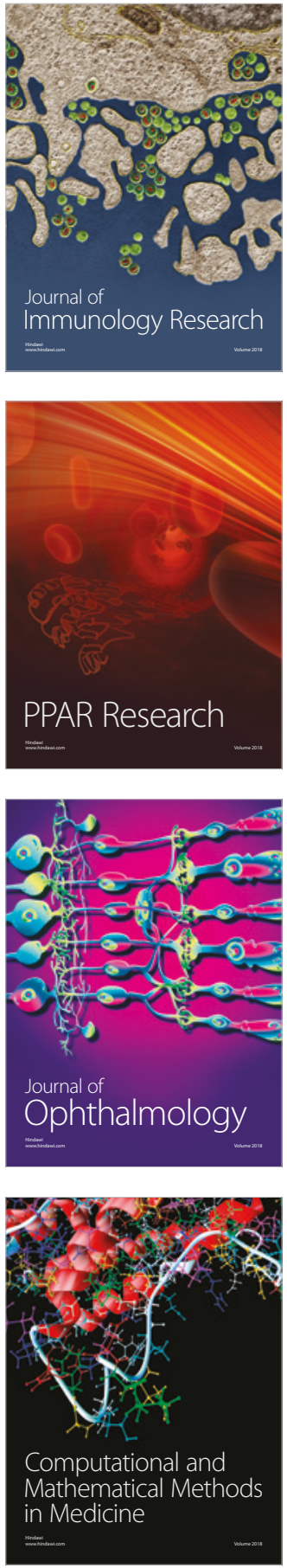

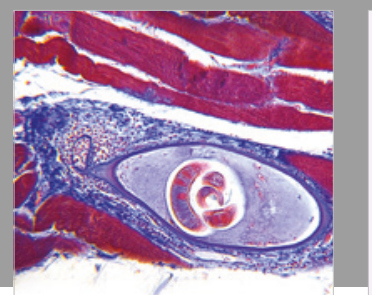

Gastroenterology Research and Practice

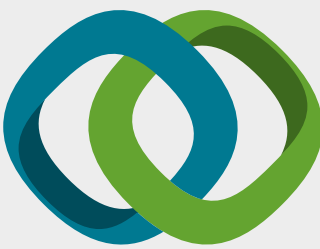

\section{Hindawi}

Submit your manuscripts at

www.hindawi.com
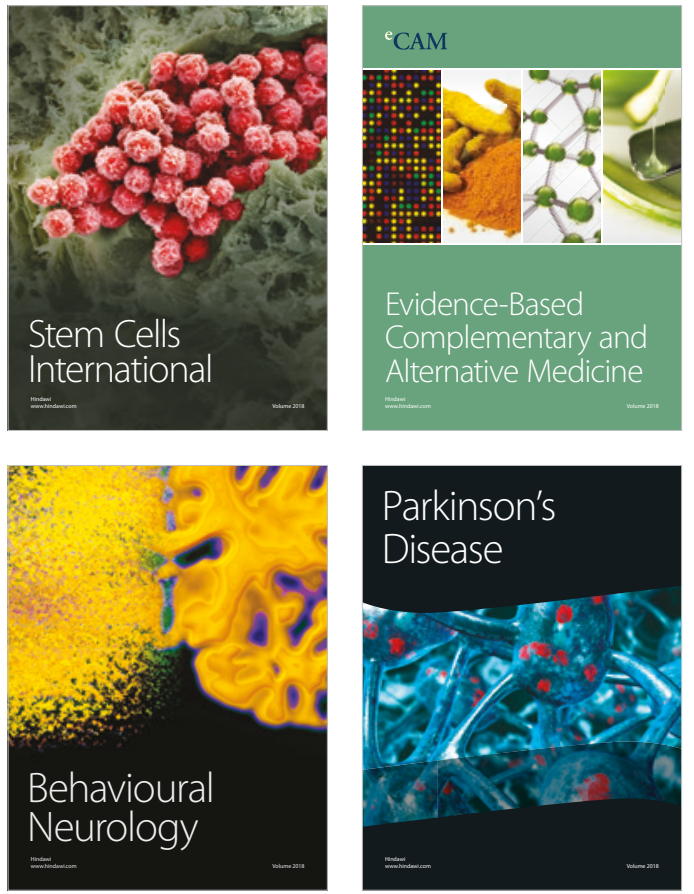

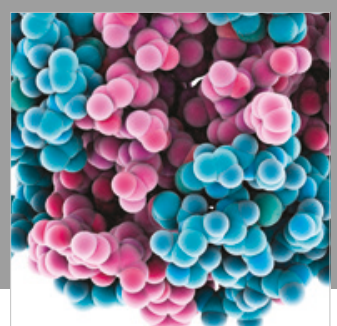

ournal of

Diabetes Research

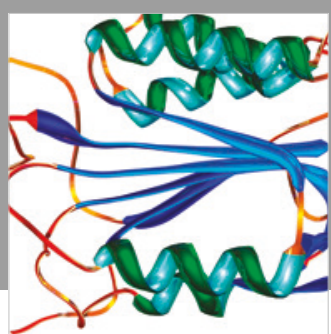

Disease Markers
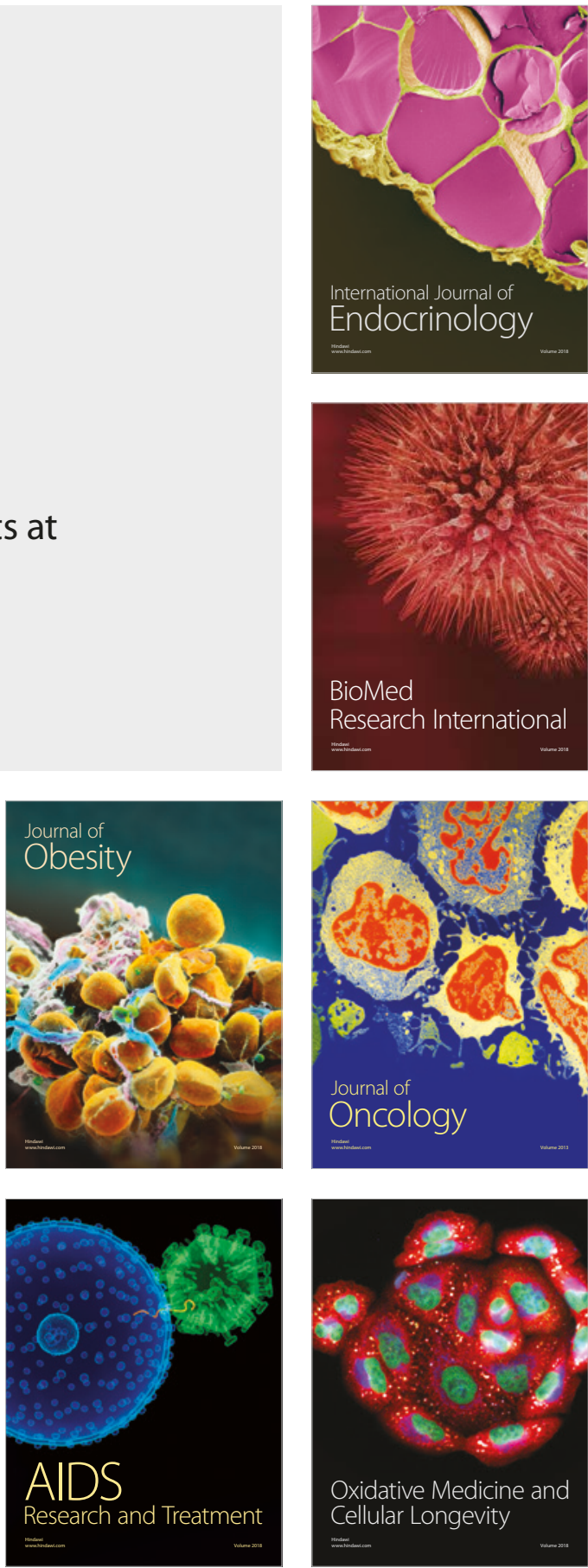